\title{
Stark broadening of Ba I and Ba II spectral lines
}

\author{
M.S. Dimitrijević ${ }^{1}$ and S. Sahal-Bréchot ${ }^{2}$ \\ 1 Astronomical Observatory, Volgina 7, 11050 Belgrade, Serbia, Yugoslavia \\ 2 Laboratoire "Astrophysique, Atomes et Molécules", Département Atomes et Molécules en Astrophysique, Unité associée au \\ CNRS No. 812, Observatoire de Paris-Meudon, 92190 Meudon, France
}

Received June 11; accepted June 14, 1996

\begin{abstract}
Using a semiclassical approach, we have calculated electron-, proton-, and ionized helium-impact line widths and shifts for $14 \mathrm{Ba}$ I and $64 \mathrm{Ba}$ II multiplets for perturber densities $10^{15}-10^{18} \mathrm{~cm}^{-3}$ and temperatures $T=2500-50000 \mathrm{~K}$ for Ba I and $5000-100000 \mathrm{~K}$ for Ba II. The results have been compared with available experimental and theoretical data.
\end{abstract}

Key words: line: profiles-atomic data

\section{Introduction}

Barium is one of thermonuclear s - processes product in stars and its overabundance is observed in $\mathrm{CH}$ subgiants, characterized by enhanced $\mathrm{Sr}$ and Ba lines, and in metal deficient barium stars, giants showing overabundance of sprocesses elements (Šleivyté \& Bartkevičius 1995). Barium lines are present in solar and stellar spectra. E.g. Komarov \& Basak (1993) have found Ba I and Ba II lines in the spectra of the Sun and of two Praesepe's stars (for Solar barium lines see also Anders \& Grevesse 1989).

Barium lines are also of interest for the investigation of laboratory plasmas. Since the research of Aulehla \& Herman (1958) who have determined neutral barium Stark effect constants by investigating metallic lines broadened by an intermolecular field, Stark broadening of $\mathrm{Ba}$ I and $\mathrm{Ba}$ II lines has been considered experimentally and theoretically in a number of articles. Kato et al. (1984) investigated wavelength shifts of $\mathrm{Ba}$ I and $\mathrm{Ba}$ II lines emitted by an inductively coupled plasma. Manning et al. (1990) performed a study of the effect of pressure and electron density on wavenumber position for $\mathrm{Ba}$ II lines. Experimental Stark broadening parameters for ionized barium lines of Jaeger (1969), obtained with the help of a discharge sliding along the surface of a liquid jet, Purić \& Konjević (1972), where the plasma source was a T-tube,

* Tables 1 and 2 are only available in electronic form: see the Editorial in A\&AS 1994, Vol. 103, No. 1.
Hadžiomerspahić et al. (1973, superseeding according to Konjević \& Wiese 1976, the similar work of Platiša et al. 1971), with Z-pinch as the experimental apparatus, and of Fleurier et al. (1987), provided with a plasma jet, have been critically reviewed in Konjević \& Wiese (1976) and Konjević et al. (1984b).

Stark widths of Ba II lines have been calculated by Cooper \& Oertel (1967) within the semiclassical approach taking into account hyperbolic classical perturber paths and lower level broadening. For Ba II 1, 2, 3, and 4 multiplet they give full width at half maximum (FWHM) values of $0.42 \AA, 0.84 \AA, 1.02 \AA$ and $1.20 \AA$ respectively, but without the electron temperature specified. Theoretically, Ba I lines have been investigated by Grechikhin (1969), considering their applicability to plasma diagnostics. $\mathrm{Ba}$ I and Ba II lines have been considered theoretically as well by Davis (1972), for research of a laser - generated barium plasma and, Ba II lines by Sahal-Bréchot (1969b) within the semiclassical - perturbation formalism and by Fleurier et al. (1977) within the same formalism but with the effect of Feshbach resonances included. The semiclassical calculations by using the theoretical approach developed by Griem et al. (1962) and further improved and described in detail by Jones et al. (1971) and Griem (1974), were performed by Purić et al. (1978). For Ba II $6 \mathrm{~s}^{2} \mathrm{~S}-6 \mathrm{p}^{2} \mathrm{P}^{\circ}$ multiplet, at an electron density of $N_{\mathrm{e}}=10^{17} \mathrm{~cm}^{-3}$ and electron temperature $T=15000 \mathrm{~K}$, they obtain FWHM $=0.428 \AA$. In Konjević \& Wiese (1976) and Konjević et al. (1984b) the theoretical comparison data have been calculated by W.W. Jones (private communication in Konjević \& Wiese 1976), by using the same method. Stark broadening parameters of Ba II mult. 1 and 2 , for $T=16000 \mathrm{~K}$ have been calculated also by Gorchakov \& Demkin (1978) within the semiclassical approach of Vainshtein \& Sobel'man (1959). Griem's (1968) semiempirical formula has been applied to Ba II lines in Hadžiomerspahić et al. (1973), Fleurier et al. (1977) and Dimitrijević \& Konjević (1981). Moreover, Dimitrijević \& Konjević (1981) performed for Ba II $6 \mathrm{~s}^{2} \mathrm{~S}-6 \mathrm{p}^{2} \mathrm{P}^{\circ}$ multiplet 1 , linewidth calculations within the modified 
semiempirical method (Dimitrijević \& Konjević 1980) and within the same approach but with the Gaunt factor derived from the work of Younger \& Wiese (1979) for the perturbing transitions without the change of the principal quantum number, Lakićević (1983) estimated line widths and shifts for Ba I $6 \mathrm{~s}^{21} \mathrm{~S}-6 \mathrm{p}^{1} \mathrm{P}^{\circ}$ and $\mathrm{Ba}$ II $6 \mathrm{~s}^{2} \mathrm{~S}-6 \mathrm{p}^{2} \mathrm{P}^{\circ}$ multiplet for $T=20000 \mathrm{~K}$, on the basis of the Stark broadening parameter dependence on the ionization potential from the lower level of the corresponding transition. By using Ba II $4899.9 \AA$ and $4524.9 \AA$ lines as example, Dimitrijević \& Popović (1989) demonstrated a simple method (developed for neutrals by Vitel et al. 1988), suitable for critical evaluation of existing data and interpolation of new Stark widths along homologous sequences, by using a normalization factor for analogous transitions.

In order to continue our research of Stark broadening parameters needed for the investigation of astrophysical and laboratory plasmas and to provide the needed Stark broadening data, we have calculated within the semiclassical-perturbation formalism (Sahal-Bréchot 1969a,b) electron-, proton-, and ionized helium-impact line widths and shifts for $14 \mathrm{Ba}$ I and $64 \mathrm{Ba}$ II multiplets. A summary of the formalism for neutral emitters is given in Dimitrijević \& Sahal-Bréchot (1984), and for ionized emitters in Dimitrijević et al. (1991) and Dimitrijević \& Sahal-Bréchot (1996). We note here that the inelastic collision contribution is included in the ion-impact line widths.

\section{Results and discussion}

Energy levels for Ba I lines have been taken from Moore (1971). Roig \& Tondello (1975) have been studied the spectrum of Ba II in absorption, by flash pyrolysis. They found a general agreement with previous results obtained in emission spectra (see the critical compilation of Moore 1971) but fifteen new levels have been established as well. For Ba II lines, energy levels were taken from Moore (1971), but values for $8-12 \mathrm{p}^{2} \mathrm{P}^{\circ}, 10 \mathrm{f}^{2} \mathrm{~F}^{\circ}$ and $11 \mathrm{f}^{2} \mathrm{~F}^{\circ}$, have been taken from Roig \& Tondello (1975). Oscillator strengths have been calculated by using the method of Bates \& Damgaard (1949) and the tables of Oertel \& Shomo (1968). For higher levels, the method described by Van Regemorter et al. (1979) has been used.

In addition to electron-impact full halfwidths and shifts, Stark-broadening parameters due to proton-, and He II- impacts have been calculated. Our results for $14 \mathrm{Ba}$ I multiplets and $64 \mathrm{Ba}$ II multiplets are shown in Tables 1 and 2 (accessibles only in electronic form) respectively, for perturber densities $10^{15}-10^{18} \mathrm{~cm}^{-3}$ and temperatures $T=2500-50000 \mathrm{~K}$ for Ba I and $T=5000-100000 \mathrm{~K}$ for Ba II. We also specify a parameter $c$ (Dimitrijević \& Sahal-Bréchot 1984), which gives an estimate for the maximum perturber density for which the line may be treated as isolated when it is divided by the corresponding full width at half maximum. For each value given in Table 1, the collision volume $(V)$ multiplied by the perturber density $(N)$ is much less than one and the impact approximation is valid (Sahal-Bréchot 1969a,b). Values for $N V>0.5$ are not given and values for $0.1<N V \leq 0.5$ are denoted by an asterisk. Tabulated Stark broadening parameters are linear with perturber density for perturber densities lower than $10^{15} \mathrm{~cm}^{-3}$. When the impact approximation is not valid, the ion broadening contribution may be estimated by using the quasistatic approach (Sahal-Bréchot 1991; Griem 1974). In the region between, where neither of these two approximations is valid, a unified type theory should be used. For example in Barnard et al. (1974), a simple analytical formula for such a case is given. The accuracy of the results obtained decreases when broadening by ion interactions becomes important.

In Table 3 our results are compared with the experimental results (Jaeger 1969; Purić \& Konjević 1972; Hadžiomerspahić et al. 1973; Fleurier et al. 1977) critically selected by Konjević \& Roberts (1976); Konjević \& Wiese $(1976,1990)$ and Konjević et al. (1984a,b). One can see that large differences between particular experiments and between theory and experiment exist. An agreement exists between widths of Fleurier et al. (1977), whose experiment was critically estimated by Konjević et al. (1984b) to have the highest accuracy among Ba II experimental data, and our results for $6 \mathrm{~s}^{2} \mathrm{~S}-6 \mathrm{p}^{2} \mathrm{P}^{\circ}$ multiplet. For the shift, the best agreement is with the results of Purić \& Konjević (1972) for the same multiplet.

Our results for Stark width are in agreement with the semiclassical calculations of Cooper \& Oertel (1967) as well as with the semiclassical calculations by using the theoretical approach developed by Griem et al. (1962) and further improved and described in detail by Jones et al. (1971) and Griem (1974), performed by W.W. Jones (private communication in Konjević \& Wiese 1976), and Purić et al. (1978). Our Stark width calculation are also in agreement within the error bars of the methods with various semiempirical calculations (Hadžiomerspahić et al. 1973; Fleurier et al. 1977; Dimitrijević \& Konjević 1981) as well as with simple Stark width estimates of Lakićević (1983), on the basis of the Stark broadening parameter dependence on the ionization potential from the lower level of the corresponding transition. For Ba I $6 \mathrm{~s}^{21} \mathrm{~S}-6 \mathrm{p}^{1} \mathrm{P}^{\circ}$ Lakićević (1983) obtained FWHM $=0.48 \AA$ at an electron density of $N_{\mathrm{e}}=10^{17} \mathrm{~cm}^{-3}$ and electron temperature $T=20000 \mathrm{~K}$, and our result is $0.30 \AA$. For Ba II $6 \mathrm{~s}^{2} \mathrm{~S}-6 \mathrm{p}^{2} \mathrm{P}^{\circ}$ multiplet for the same plasma conditions, Lakićević obtains FWHM $=0.50 \AA$ and our result is $0.43 \AA \AA$.

Our results for the shift are in agreement within the error of the method with the semiclassical calculations of W.W. Jones (private communication in Konjević \& Wiese 1976), but in strong disagreement with calculations of Gorchakov \& Demkin (1978), performed within the semiclassical approach of Vainshtein \& Sobel'man (1959), with 
Table 3. Experimental Stark full widths at half maximum (Wm) and shifts ( $\mathrm{dm})$ in $\AA$ compared with theory. The Wth and dth are present semi - classical calculations. Experimental values: (a) - Fleurier et al. (1977); (b) - Jaeger (1969); (c) - Purić \& Konjević (1972); (d) - Hadžiomerspahić et al. (1973)

\begin{tabular}{|c|c|c|c|c|c|c|c|c|}
\hline $\begin{array}{c}\text { Transition } \\
\text { (Mult.) }\end{array}$ & Wawelength & $T(\mathrm{~K})$ & $\begin{array}{c}\mathrm{Ne} \\
{[10(+17)} \\
\mathrm{cm}(-3)]\end{array}$ & $\begin{array}{l}\mathrm{Wm} \\
{[\mathrm{A}]}\end{array}$ & $\begin{array}{l}\text { Wth } \\
{[\mathrm{A}]}\end{array}$ & $\begin{array}{l}\mathrm{dm} \\
{[\mathrm{A}]}\end{array}$ & $\begin{array}{l}\text { dth } \\
{[\mathrm{A}]}\end{array}$ & Ref. \\
\hline \multirow{9}{*}{$\begin{array}{c}5 \mathrm{~d}-6 \mathrm{p} \\
(2)\end{array}$} & \multirow[t]{5}{*}{6141.72} & 13000 & 1.13 & 0.50 & 0.91 & - & - & $\mathrm{a}$ \\
\hline & & 13200 & 1 & 1.58 & 0.80 & - & - & b \\
\hline & & 16800 & 1 & - & - & 0.07 & 0.002 & $\mathrm{c}$ \\
\hline & & 27100 & 1 & 0.28 & 0.62 & - & - & d \\
\hline & & 31700 & 1 & 0.28 & 0.59 & - & - & d \\
\hline & \multirow[t]{3}{*}{6496.9} & 16800 & 1 & - & - & 0.07 & 0.002 & c \\
\hline & & 27100 & 1 & 0.28 & 0.62 & 0.05 & 0.002 & d \\
\hline & & 31700 & 1 & 0.28 & 0.59 & - & - & d \\
\hline & 5853.7 & 13200 & 1 & 1.32 & 0.80 & - & - & $\mathrm{b}$ \\
\hline \multirow{8}{*}{$\begin{array}{c}6 s-6 p \\
(1)\end{array}$} & \multirow[t]{4}{*}{4554.03} & 13000 & 1.13 & 0.49 & 0.58 & -0.050 & -0.095 & $\mathrm{a}$ \\
\hline & & 13200 & 1 & 0.80 & 0.51 & - & - & $\mathrm{b}$ \\
\hline & & 16800 & 1 & - & - & -0.06 & -0.076 & $\mathrm{c}$ \\
\hline & & 27100 & 1 & 0.26 & 0.39 & - & - & d \\
\hline & \multirow[t]{4}{*}{4934.09} & 13000 & 1.13 & 0.49 & 0.58 & -0.050 & -0.095 & $\mathrm{a}$ \\
\hline & & 13200 & 1 & 0.94 & 0.51 & - & - & $\mathrm{b}$ \\
\hline & & 16800 & 1 & - & - & -0.07 & -0.076 & $\mathrm{c}$ \\
\hline & & 27100 & 1 & 0.24 & 0.39 & - & - & d \\
\hline \multirow{4}{*}{$\begin{array}{c}6 \mathrm{p}-6 \mathrm{~d} \\
(4)\end{array}$} & 4130.6 & 13200 & 1 & 1.24 & 1.07 & - & - & $\mathrm{b}$ \\
\hline & 4166.0 & 13200 & 1 & 1.26 & 1.07 & - & - & $\mathrm{b}$ \\
\hline & \multirow[t]{2}{*}{3891.8} & 16800 & 1 & - & - & 0.26 & 0.49 & d \\
\hline & & 31700 & 1 & 0.28 & 0.93 & 0.33 & 0.40 & d \\
\hline $6 p-7 s$ & 4899.9 & 13200 & 1 & 1.48 & 1.10 & - & - & $\mathrm{b}$ \\
\hline (3) & 4524.9 & 13200 & 1 & 1.28 & 1.10 & - & - & b \\
\hline
\end{tabular}

the semi the empirical calculations of Purić \& Konjević (1972) and with the simple estimates of Lakićević (1983). New high precision measurements of Stark broadening parameters for Ba I and Ba II lines will be of interest for the development of theoretical methods for heavy atoms and ions.

\section{Acknowledgements. This}

work is a part of the project "Astrometrical, Astrodynamical and Astrophysical Investigations", supported by Ministry of Science and Technology of Serbia.

\section{References}

Anders E., Grevesse N., 1989, Geochim. Cosmochim. Acta 53, 197

Aulehla E., Herman L., 1958, C. R. H. Acad. Sci. 246, 1676

Barnard A.J., Cooper J., Smith E.W., 1974, JQSRT 14, 1025

Bates D.R., Damgaard A., 1949, Trans. Roy. Soc. London Ser. A 242,101

Cooper J., Oertel G.K., 1967, Phys. Rev. Lett. 18, 985

Davis J., 1972, JQSRT 12, 1351
Dimitrijević M.S., Konjević N., 1980, JQSRT 24, 451

Dimitrijević M.S., Konjević N., 1981, A\&A 102, 93

Dimitrijević M.S., Popović M.M., 1989, A\&A 217, 203

Dimitrijević M.S., Sahal-Bréchot S., 1984, JQSRT 31, 301

Dimitrijević M.S., Sahal-Bréchot S., 1996, Phys. Scr. 54, 50

Dimitrijević M.S., Sahal-Bréchot S., Bommier V., 1991, A\&AS 89,581

Fleurier C., Sahal-Bréchot S., Chapelle J., 1977, JQSRT 17, 595

Gorchakov L.V., Demkin V.P., 1978, Izv.Vysshikh Uchebnykh Zavedenij, Fizika 4, 113

Grechikhin L.I., 1969, J. Appl. Spectrosc. (USSR) 10, 870

Griem H.R., 1968, Phys. Rev. 165, 258

Griem H.R., 1974, Spectral Line Broadening by Plasmas. Academic Press, New-York

Griem H.R., Baranger M., Kolb A.C., Oertel G.K., 1962, Phys. Rev. 125, 177

Hadžiomerspahić D., Platiša M., Konjević N., Popović M., 1973, Z. Physik 262, 169

Jaeger H., 1969, Z. Physik 223, 19

Jones W.W., Benett S.M., Griem H.R., 1971, Calculated Electron Impact Broadening Parameters for Isolated 
Spectral Lines from the Singly Charged Ions: Lithium through Calcium, Techn. Report No. 71-128, University of Maryland, College Park, MD

Kato K., Fukushima H., Nakajima T., 1984, Spectrochim. Acta B 39, 979

Komarov N.S., Basak N. Yu., 1993, Astron. Zh. 70, 111

Konjević N., Roberts J.R., 1976, J. Phys. Chem. Ref. Data 5, 209

Konjević N., Wiese W.L., 1976, J. Phys. Chem. Ref. Data 5, 259

Konjević N., Wiese W.L., 1990, J. Phys. Chem. Ref. Data 19, 1307

Konjević N., Dimitrijević M.S., Wiese W.L., 1984a, J. Phys. Chem. Ref. Data 13, 619

Konjević N., Dimitrijević M.S., Wiese W.L., 1984b, J. Phys. Chem. Ref. Data 13, 649

Lakićević I.S., 1983, A\&A 127, 37

Manning T.J., Winefordner J.D., Palmer B.A., Hof D.E., 1990, Spectrochim. Acta B 45, 1031
Moore C.E., 1971, Atomic Energy Levels II, NSRDS-NBS 35, Washington

Oertel G.K., Shomo L.P., 1968, ApJS 16, 175

Platiša M., Purić J., Konjević N., Labat J., 1971, A\&A 15, 325

Purić J., Dimitrijević M.S., Lakićević I.S., 1978, Phys. Lett. A 67,188

Purić J., Konjević N., 1972, Z. Physik. 249, 440

Roig R.A., Tondello G., 1975, J. Opt. Soc. 65, 829

Sahal-Bréchot S., 1969a, A\&A 1, 91

Sahal-Bréchot S., 1969b, A\&A 2, 322

Sahal-Bréchot S., 1991, A\&A 245, 322

Šleivyté J., Bartkevičius A., 1995, Vilniaus Astron. Obs. Biul. 85,3

Van Regemorter H., Hoang Binh Dy Prud'homme M., 1979, J. Phys. B 12, 1073

Vainshtein L.A., Sobel'man I.I., 1959, Opt. Spektrosk. 6, 440

Vitel Y., Skowronek M., Dimitrijević M.S., Popović M.M., 1988, A\&A 200, 285

Younger S.M., Wiese W.L., 1979, JQSRT 22, 161 